\title{
Pitfalls of Diagnosis in a Case of Celiac Disease with Allergic Manifestations
}

\author{
Sur Genel ${ }^{1,}$, Samasca Gabriel ${ }^{2,3}$, Flonca Emanuela ${ }^{3}$, Rus Anca $^{3}$, Abrudan Carmen ${ }^{3}$, Donca Valer ${ }^{4}$, Deleanu Diana $^{2}$ \\ ${ }^{1}$ Department of Pediatrics II, Iuliu Hatieganu University of Medicine and Pharmacy, Cluj-Napoca, Romania \\ ${ }^{2}$ Department of Immunology, Iuliu Hatieganu University of Medicine and Pharmacy, Cluj-Napoca, Romania \\ ${ }^{3}$ Emergency Hospital for Children, Cluj-Napoca, Romania \\ ${ }^{4}$ Clujana Municipal Hospital, Cluj-Napoca, Romania \\ *Corresponding author: surgenel@yahoo.com
}

Received November 10, 2014; Revised November 12, 2014; Accepted November 19, 2014

\begin{abstract}
Celiac disease has many manifestations and the diagnosis is often difficult. We report the case of a child to which extradigestive manifestations of celiac disease masked celiac disease evolution. The association of proven allergic manifestations slowed celiac disease diagnosis.
\end{abstract}

Keywords: celiac disease, child, extradigestive manifestations

Cite This Article: Sur Genel, Samasca Gabriel, Flonca Emanuela, Rus Anca, Abrudan Carmen, Donca Valer", and Deleanu Diana, "Pitfalls of Diagnosis in a Case of Celiac Disease with Allergic Manifestations." International Journal of Celiac Disease, vol. 2, no. 4 (2014): 142-143. doi: 10.12691/ijcd-2-4-7.

\section{Introduction}

American Association of Family Physicians emphasized the following: "Ingested protein does not normally provoke an immune response. This phenomenon is termed "oral tolerance." Patients who exhibit true allergy to an ingested protein (e.g., milk or soy protein) have a typical IgE-mediated response consisting of urticaria, angioedema, and bronchoreactivity. The autoimmunity in gluten-sensitive enteropathy involves plasma cells that produce IgA and IgG; there is little or no IgE involvement" [1]. So, there is a little or no $\operatorname{IgE}$ involvement in celiac disease. But over the time were identified many masks of celiac disease $[2,3,4]$. In all cases of suspected celiac disease, the best solution is celiac disease screening with IgA antitissue transglutaminase antibodies [5].

We present a case that was a mask of celiac disease, meaning that the skin manifestations occurred but were identified as allergic manifestations, not extradigestive manifestations of celiac disease.

\section{Case Report}

The child was born to term with a weight of $3200 \mathrm{~g}$ and without signs of fetal distress. He was naturally fed up at the age of 3 months. Then he got mixed food.

The parents introduced diversify food in child nutrition to the age of 6 months. He presented 3 modified and pasty stools per day at the age of 1 year, with poor weight gain. Pruritic and erythematous macular eruptions occurred simultaneously on skin; sometimes appeared papules and vesicles. The medical doctor interpreted this eruption as being within a food allergy; for that reason Aerius
(Desloratadine) is given for 1 month. The evolution of cutaneous manifestations was good, meaning that these erythematous macules disappeared at the end of treatment. 2-3 modified stools per day persisted with the same weight stagnation. At the age of 2 years, our patient presented up to 5 episodes of aqueous and pasta diarrhea per day. The child required the administration of infusion, electrolyte rebalancing with glucose, saline and $\mathrm{Na}$ and $\mathrm{K}$ electrolytes. Probiotics that contain Sacharomices boulardi ( 1 / day Flucovit) were also introduced in treatment.

Clinical exam on hospitalization showed a slightly influenced general feeling, pale skin and mucous membranes, subcutaneous tissue underrepresented in totally, with a distended abdomen. Laboratory examinations revealed the existence of a deficiency anemia: hemoglobin $11.1 \mathrm{~g} / \mathrm{dl}$ (normal values 12.1-17.2 g/dl), hematocrit 35\% (normal values $36.8-50.2 \%$ ). In these circumstances, the medical doctor thought about the possible existence of celiac disease which was suggested by the clinical appearance of diarrhea syndrome and deficiency syndrome, namely anemia. Celiac disease screening examinations showed the following: $\operatorname{IgA}$ tissue transglutaminase antibodies = positive $61 \mathrm{U} / \mathrm{ml}$ (normal values $<10 \mathrm{U} / \mathrm{ml}$ ), IgA antiendomisial antibodies $=$ positive (indirect immunofluorescence). Positive values of screening tests supported the diagnosis of celiac disease and biopsy of the intestinal mucosa showed us a Marsh stage 3a. The laboratory examinations for skin manifestations showed us a high level of total $\mathrm{IgE}=168 \mathrm{UI} / \mathrm{ml}$ (normal values $<10 \mathrm{UI} / \mathrm{ml}$ ) and a beginning of sensitization to cow's milk and egg white.

Under these conditions, the medical doctor decided a gluten-free diet (first without milk) for the patient. Digestive manifestations evolution was favorable, meaning that the child presented 1 stool per day and began 
a slight weight gain. The child had a gain of $500 \mathrm{~g}$ after a month with gluten-free diet.

\section{Particularities of the Case}

Extradigestive manifestations of celiac disease, namely skin eruptions can mask celiac disease evolution. The existence of these manifestations was attributed to food allergies in our case. Celiac disease was questioned and investigated only in a stage in which were obvious clinical manifestations. Under the gluten-free diet, the child had a good evolution of digestive symptoms with weight gain.

\section{Acknowledgement}

This paper was published under the frame of European Social Found, Human Resources Development Operational Programme 2007-2013, project no. POSDRU/159/1.5/S/138776.

\section{References}

[1] Nelsen DA. JR. Gluten-sensitive enteropathy (celiac disease). Am Family Physician 2002; 66: 2259-2266.

[2] Husby S, Koletzko S, Korponay-Szabó IR, Mearin ML, Phillips A, Shamir R, Troncone R, Giersiepen K, Branski D, Catassi C, Lelgeman M, Mäki M, Ribes-Koninckx C, Ventura A, Zimmer KP ESPGHAN Working Group on Coeliac Disease Diagnosis; ESPGHAN Gastroenterology Committee; European Society for Pediatric Gastroenterology, Hepatology, and Nutrition. European Society for Pediatric Gastroenterology, Hepatology, and Nutrition guidelines for the diagnosis of coeliac disease. J Pediatr Gastroenterol Nutr 54: 136-160.

[3] Sur G, Floca E, Sur L, Sur D, Samasca G. Clinical presentation of celiac disease; Masks therapeutic perspectives of celiac disease. Pharmaceutica Analytica Acta 2013; 4: 1000228.

[4] Reilly NR, Fasano A, Green PH. Presentation of celiac disease. Gastrointest Endosc Clin N Am 2012; 22: 613-621.

[5] Samașca G, Iancu M, Farcău D, Butnariu A, Pop T, Pîrvan A, Andreica M, Miu N, Cristea V, Dejica D. IgA anti-tissue transglutaminase antibodies, first line in the diagnosis of celiac disease. Clin Lab. 2011; 57: 695-701. 